\title{
NMDARs Mediate the Role of Monoamine Oxidase A in Pathological Aggression
}

\author{
Marco Bortolato, ${ }^{1,3,6 *}$ Sean C. Godar, ${ }^{1 \star}$ Miriam Melis, ${ }^{4}$ Alessio Soggiu, ${ }^{4}$ Paola Roncada, ${ }^{8}$ Angelo Casu, ${ }^{4}$ Giovanna Flore, ${ }^{7}$ \\ Kevin Chen, ${ }^{1}$ Roberto Frau, ${ }^{5,6}$ Andrea Urbani, ${ }^{3}$ M. Paola Castelli, ${ }^{4,6}$ Paola Devoto, ${ }^{5,6}$ and Jean C. Shih ${ }^{1,2}$ \\ Departments of ${ }^{1}$ Pharmacology and Pharmaceutical Sciences, and ${ }^{2}$ Cell and Neurobiology, University of Southern California, Los Angeles, California 90089, \\ ${ }^{3}$ Santa Lucia Foundation-IRCCS (Istituto Di Ricovero e Cura a Carattere Scientifico), 00143 Rome, Italy, ${ }^{4}$ Department of Neuroscience "Bernard B. Brodie," \\ 5"Guy Everett" Laboratory, Department of Neuroscience "Bernard B. Brodie," ${ }^{6}$ Tourette Syndrome Center, and ${ }^{7}$ Department of Cardiovascular and \\ Neurological Sciences, University of Cagliari, 09124 Cagliari, Italy, and ${ }^{8}$ Istituto Sperimentale Italiano "Lazzaro Spallanzani,” 20134 Milan, Italy
}

Converging evidence shows that monoamine oxidase A (MAO A), the key enzyme catalyzing serotonin (5-hydroxytryptamine; 5-HT) and norepinephrine (NE) degradation, is a primary factor in the pathophysiology of antisocial and aggressive behavior. Accordingly, male MAO A-deficient humans and mice exhibit an extreme predisposition to aggressive outbursts in response to stress. As NMDARs regulate the emotional reactivity to social and environmental stimuli, we hypothesized their involvement in the modulation of aggression mediated by MAO A. In comparison with WT male mice, MAO A KO counterparts exhibited increases in 5-HT and NE levels across all brain regions, but no difference in glutamate concentrations and NMDAR binding. Notably, the prefrontal cortex (PFC) of MAO A KO mice exhibited higher expression of NR2A and NR2B, as well as lower levels of glycosylated NR1 subunits. In line with these changes, the current amplitude and decay time of NMDARs in PFC was significantly reduced. Furthermore, the currents of these receptors were hypersensitive to the action of the antagonists of the NMDAR complex (dizocilpine), as well as NR2A (PEAQX) and NR2B (Ro 25-6981) subunits. Notably, systemic administration of these agents selectively countered the enhanced aggression in MAO A KO mice, at doses that did not inherently affect motor activity. Our findings suggest that the role of MAO A in pathological aggression may be mediated by changes in NMDAR subunit composition in the PFC, and point to a critical function of this receptor in the molecular bases of antisocial personality.

\section{Introduction}

Antisocial and aggressive behaviors have a profound socioeconomic impact (Reiss, 1993), yet current strategies to reduce these staggering phenomena are extremely unsatisfactory. In particular, the clinical management of these entities remains problematic, in view of their heterogeneous symptomatic manifestations and the substantial limitations of available therapies (Cherek et al., 2006; Harris and Lurigio, 2007). Current theoretical perspectives posit the existence of multiple subtypes of pathological aggression, featuring distinct psychological profiles and neurobiological underpinnings (Blair, 2004); in particular, reactive aggression, the antisocial trait characterized by impulsive

Received Jan. 12, 2012; revised May 2, 2012; accepted May 7, 2012.

Author contributions: M.B., S.G., P.R., A.U., and J.C.S. designed research; M.B., S.G., M.M., A.S., P.R., A.C., G.F., R.F., A.U., M.P.C., and P.D. performed research; K.C. and J.C.S. contributed unpublished reagents/analytic tools; M.B., S.G., M.M., A.S., P.R., and A.U. analyzed data; M.B., S.G., and M.M. wrote the paper.

The present study was supported by National Institutes of Health Grants R01MH39085 (to J.C.S.) and R21HD070611 (to M.B.), as well as the Boyd and Elsie Welin Professorship (to J.C.S.) and the University of Southern California Zumberge Research Individual Grant (to M.B.). We are grateful to Anna L. Scott, Valentina Bini, Simone Tambaro, Felix Li, and Andrea Gochi for their valuable support in the execution of the experiments.

The authors declare no competing financial interests.

*M.B. and S.C.G. contributed equally to the study.

Correspondence should be addressed to either Dr. Marco Bortolato or Jean C. Shih, Department of Pharmacology and Pharmaceutical Sciences, School of Pharmacy, University of Southern California, Room 527 (M.B.) or Room 518 (J.C.S.), 1985 Zonal Avenue, Los Angeles, CA 90089. E-mail: bortolat@usc.edu, or jcshih@usc.edu.

DOI:10.1523/JNEUROSCI.0225-12.2012

Copyright $\odot 2012$ the authors $\quad 0270-6474 / 12 / 328574-09 \$ 15.00 / 0$ and hostile responses to stressful contingencies, has been shown to be regulated by monoamine oxidase $\mathrm{A}$ (MAO A), the major enzyme catalyzing the oxidative deamination of brain serotonin (5-hydroxytryptamine; 5-HT) and norepinephrine (NE) (Shih et al., 1999; Bortolato et al., 2008).

The role of MAO A in reactive aggression was first highlighted by the characterization of Brunner syndrome, a rare X-linked condition featuring a nonsense mutation of $M A O A$ gene, marked increases in urinary 5-HT levels, and extreme predisposition to violent outbursts in response to unexpected stressors (Brunner et al., 1993). Subsequent investigations documented that male carriers of low-activity $M A O A$ allelic variants had significantly higher susceptibility to develop impulsive aggression as a longterm sequela of early-life maltreatment and abuse (Caspi et al., 2002; Kim-Cohen et al., 2006; Widom and Brzustowicz, 2006; Weder et al., 2009). Finally, recent findings indicate that, in males, the severity of antisocial traits is inversely correlated with MAO A catalytic activity in the brain (Alia-Klein et al., 2008).

Cogent neuroimaging evidence indicates that the role of $\mathrm{MAO}$ A in the pathophysiology of reactive aggression involves the forebrain circuits regulating social and environmental assessment (Buckholtz and Meyer-Lindenberg, 2008); the neurochemical bases of this phenomenon, however, remain elusive. An optimal tool to obviate this limitation and identify novel therapeutic targets for aggression is afforded by MAO A KO mice. These mutants display a spectrum of behavioral abnormalities strikingly 
isotypic with those observed in Brunner syndrome, including highly aggressive, maladaptive, and perseverative responses to perceived stress (Cases et al., 1995; Kim et al., 1997; Bortolato and Shih, 2011; Godar et al., 2011). Notably, these abnormal behaviors are mediated by forebrain regions (Chen al, 2007).

A growing body of literature documents that the NMDARs serve a central function in the regulation of information processing (Daw et al., 1993), as well as aggressive and defensive responses (Gould and Cameron, 1997; Carobrez et al., 2001). NMDARs are ionotropic channels formed by the combination of different subunits, including NR1 and the four members of the NR2 family (termed A through D) (Cull-Candy et al., 2001). NR1 is the obligatory subunit and has eight known splice variants, resulting from the combination of three alternatively splicing cassettes (N1, C1, and C2) in its coding region (Durand et al., 1993). Notably, the function and subunit composition of NMDARs are highly influenced by monoamine neurotransmitters (Boyer et al., 1998; Masuko et al., 2004; Yuen et al., 2005). This background prompted us to hypothesize that the role of MAO A in reactive aggression may be mediated by alterations of NMDARs. Thus, in the present study we investigated the expression and function of NMDARs in the forebrain of MAO A KO mice, compared with their WT littermates.

\section{Materials and Methods}

Animals. We used 3- to 4-month-old, experimentally naive 129 S6 adult male mice, weighing $25-30 \mathrm{~g}$. MAO A ${ }^{\mathrm{A} 863 \mathrm{~T}} \mathrm{KO}$ were generated as previously described (Scott et al., 2008). Animals were housed in group cages with ad libitum access to food and water. The room was maintained at $22^{\circ} \mathrm{C}$, on a $12 \mathrm{~h}$ light/dark cycle. In all experiments, male MAO A KO hemizygous mice were compared with their WT littermates. As Maoa gene is located on the X chromosome (Lan et al., 1989), no heterozygous or homozygous male mice are available. Animals from at least three different litters were used, to minimize potential litter effects. Experimental procedures were in compliance with the National Institutes of Health guidelines and approved by the Animal Use Committees of the University of Southern California and University of Cagliari.

Drugs. The NMDAR antagonist dizocilpine (MK-801; SigmaAldrich), the NR2A subunit antagonist PEAQX (Tocris Bioscience), and the NR2B subunit antagonist Ro 25-6981 (Tocris Bioscience) were dissolved in saline $0.9 \%$ and administered intraperitoneally in an injection volume of $10 \mathrm{ml} / \mathrm{kg}$.

Measurement of brain-regional 5-HT, NE, and glutamate levels by HPLC. Neurotransmitter content was measured in the prefrontal cortex (PFC), striatum, hippocampus, and midbrain of WT and MAO A KO mice. Following decapitation, brain regions were rapidly dissected, frozen in liquid nitrogen, and stored at $-80^{\circ} \mathrm{C}$. For $5-\mathrm{HT}$ and NE analyses, regions were homogenized in a solution containing $0.1 \mathrm{M}$ trichloroacetic acid, 10 mM sodium acetate, and $0.1 \mathrm{~mm}$ EDTA; $1 \mu \mathrm{m}$ isoproterenol was used as an internal standard. The homogenates were sonicated and centrifuged, and the supernatants were used for HPLC analysis. 5-HT and NE were used as standards (Sigma-Aldrich). The protein concentrations were determined using the pellet using the bicinchoninic acid kit (Pierce), following the manufacturer's protocol. The mobile phase was the same as the homogenization buffer (excluding the isoproterenol) with 7\% methanol for detection of 5-HT and 5-HIAA. NE was quantified separately using trichloroacetic acid mobile phase solution without methanol. The mobile phases were filtered and deaerated, and the pump speed (LC-6A liquid chromatograph, Shimadzu) was kept at $1.5 \mathrm{ml} / \mathrm{min}$. The reverse-phase column used was a Rexchrom S50100-ODS C18 column with a length of $25 \mathrm{~cm}$ and an internal diameter of $4.6 \mathrm{~mm}$ (Regis Technologies). The compounds were measured at $+0.7 \mathrm{~V}$ using an electrochemical detector (L-ECD-6A, Shimadzu).

For glutamate measurement, experimental procedures were based on previously described methods (Clarke et al., 2007). Briefly, tissues were homogenized $(1: 50, \mathrm{w} / \mathrm{v})$ by sonication in buffer solution $(0.1 \mathrm{M}$ citric acid, $0.1 \mathrm{~m}$ sodium dihydrogen phosphate monohydrate, $5.6 \mathrm{~mm}$ octane sulfonic acid, $10 \mu \mathrm{M}$ EDTA, $10 \%$ methanol $(\mathrm{v} / \mathrm{v})$, pH 2.8 with $5 \mathrm{M}$ $\mathrm{NaOH}$ ), centrifuged at $14,000 \mathrm{rpm}$ for $15 \mathrm{~min}$ at $4^{\circ} \mathrm{C}$. The resulting supernatant was filtered on micro-spin centrifuge tubes $(0.22 \mu \mathrm{m}$ nylon filter) and stored at $-80^{\circ} \mathrm{C}$ until derivatized with 2,3-naphthalene dicarboxaldehyde (NDA, Fluka) and analyzed by HPLC. The supernatant was diluted 1:100 in water. Diluted supernatant ( $40 \mu \mathrm{l})$ was mixed with $40 \mu \mathrm{l}$ of borate buffer ( $500 \mathrm{~mm}, \mathrm{pH} 8.7), 240 \mu \mathrm{l}$ of KCN (10 mM) and $40 \mu \mathrm{l}$ of $\mathrm{NDA}$ ( $5 \mathrm{~mm}$ in $\mathrm{CH}_{3} \mathrm{OH}$ ); the solution was vortex-mixed and left 4 min at room temperature for derivatization, then $15 \mu \mathrm{l}$ were injected into the HPLC. The chromatographic system was a Waters 515 pump, an Agilent 1200 series autosampler, and a Picometrics ZetaLIF (Laser Induced Fluorescence) detector, equipped with a Helium/Cadmium laser (CVI Melles-Griot) working at $\lambda_{\mathrm{ex}}=442 \mathrm{~nm}$ and $\lambda_{\mathrm{em}}=490 \mathrm{~nm}$. Separation was performed on Symmetry C18 columns $(150 \times 3.0 \mathrm{~mm}, 3.5 \mu \mathrm{m}$, Waters). Mobile phase was $50 \mathrm{~mm}$ sodium acetate ( $\mathrm{pH} 5$ with glacial acetic acid) and methanol (48:52). Peaks were quantified following standard curve calibration by custom software (Millennium, Waters).

Quantitative autoradiography of $\left[{ }^{3} \mathrm{H}\right]$ dizocilpine binding sites. Animals were anesthetized with halothane and killed by decapitation; brains were rapidly removed, snap-frozen, and stored at $-80^{\circ} \mathrm{C}$ until sectioning. Coronal sections (12-16 $\mu \mathrm{m}$ thick) were prepared using a cryostat at $-20^{\circ} \mathrm{C}$, thaw-mounted onto Superfrost Plus slides (BDH) and stored with desiccant at $-20^{\circ} \mathrm{C}$ until use. The following regions were analyzed: cingulate cortex areas 3 and $1(\mathrm{AP}+2.2)$, caudate-putamen, nucleus accumbens core and shell (AP +1.10), CA1, CA2, CA3 hippocampal fields, dentate gyrus and basolateral amygdala (AP - 1.58; AP -1.82). Stereotaxic coordinates for each region were based on the atlas by Paxinos and Franklin (2001). Adjacent sections to those used for autoradiography were collected and stained with Neutral Red to facilitate the identification of the selected brain areas. [ ${ }^{3} \mathrm{H}$ ]Dizocilpine binding autoradiography was performed as previously described (Newell et al., 2007). Briefly, tissue slides were incubated at room temperature for $2.5 \mathrm{~h}$ in 30 mM HEPES buffer, pH 7.5, containing $100 \mu \mathrm{m}$ glycine, $100 \mu \mathrm{M}$ glutamate, $1 \mathrm{~mm}$ EDTA and $10 \mathrm{~nm}\left[{ }^{3} \mathrm{H}\right]$ dizocilpine (specific activity: $27.5 \mathrm{Ci} / \mathrm{mmol}$, PerkinElmer). Nonspecific binding was determined in adjacent brain sections in the presence of $20 \mu \mathrm{M}$ unlabeled $(+)$-dizocilpine. Following the incubation, tissue slides were rinsed twice at $4^{\circ} \mathrm{C}$ for $20 \mathrm{~min}$ each in ice-cold HEPES buffer ( $30 \mathrm{~mm}, \mathrm{pH} 7.5$ ) containing 1 mM EDTA, dipped in ice-cold deionized water and then air-dried. Dried tissue sections and slide-mounted ${ }^{3} \mathrm{H}$-microscale standards (RPA 501 and 505, GE Healthcare Life Sciences) were placed in a BAS cassette (Fujifilm) with a BAS5000 imaging plate. The resulting images were analyzed with an AIDA imaging system (Raytest), and optical densities were transformed into levels of bound radioactivity (fmol/mg protein) with gray values generated by coexposed ${ }^{3} \mathrm{H}$-standards.

Immunoblotting of NMDAR subunits. Adult male MAO A KO and WT mice (3 months old) were killed by cervical dislocation. Brains were rapidly removed and regions of interest (PFC, hippocampus, and striatum) were harvested on ice. Tissues were weighed and homogenized with a Teflon-glass homogenizer in ice-cold $0.32 \mathrm{~m}$ sucrose $(1: 20 \mathrm{w} / \mathrm{v})$, containing 1:100 Protease Inhibitor Cocktail (Sigma-Aldrich). The homogenates were centrifuged $\left(1000 \times g, 10 \mathrm{~min}, 4^{\circ} \mathrm{C}\right)$ to remove nuclei and large debris $(\mathrm{P} 1)$. The supernatants were centrifuged $(20,000 \times g, 20 \mathrm{~min}$, $\left.4^{\circ} \mathrm{C}\right)$ to obtain crude synaptosomal fractions (P2) that were stored at $-80^{\circ} \mathrm{C}$ until used. Each P2 was suspended (1:10, original w/v) in a solution of $7 \mathrm{~m}$ urea, $2 \mathrm{~m}$ thiourea, 4\% CHAPS, 2\% Ampholine, $\mathrm{pH} 3.5-10$, and $65 \mathrm{~mm}$ DTT. Suspensions were homogenized under mechanical stirring for $2 \mathrm{~h}$ and then centrifuged at $14,000 \times g$ for $30 \mathrm{~min}$ to remove cellular debris and insoluble materials. Protein concentrations were determined using the 2D-Quant Kit (NovaBlot, GE Healthcare Life Sciences). Ten micrograms of proteins were separated by SDS-PAGE using $4-12 \%$ gradient gels, and then transferred with a semidry apparatus (GE Healthcare Life Sciences) onto a polyvinylidene fluoride (PVDF) membrane in blotting buffer (192 mm glycine, $25 \mathrm{~mm}$ Tris, $20 \%$ methanol, and $0.1 \% \mathrm{SDS}$ ) at $0.8 \mathrm{~mA} / \mathrm{cm}^{2}$ for $60 \mathrm{~min}$. Membranes were rinsed in PBST buffer ( $1 \times$ PBS and $0.1 \%$ Tween 20, pH 7.4). After rinsing, blots were blocked for $1 \mathrm{~h}$ with 5\% nonfat dry milk (NFM) in PBST and incubated overnight at $4^{\circ} \mathrm{C}$ with one of the following primary antibodies: anti- 
NMDA NR1 (Cell Signaling Technology), anti-NMDA NR1 subunit splice cassette N1 (AbD Serotec), anti-NMDA-NR1 subunit splice cassette C2 (Millipore), anti-NMDA NR2C (Sigma-Aldrich), anti-NMDA NR2D (Millipore) and anti- $\beta$-actin (Cell Signaling Technology), as per the manufacturer's instructions. Membranes were rinsed in PBST and incubated for $1 \mathrm{~h}$ with anti-Mouse and anti-Rabbit IgG secondary antibodies (SigmaAldrich) conjugated to horseradish peroxidase (HRP) diluted at 1:15,000 in PBST-5\% NFM. For glycosylation analyses, proteins from 1-DE were transferred to PVDF membranes and incubated with $1 \mu \mathrm{g} / \mathrm{ml}$ Concanavalin A-Biotin (Sigma) in PBS containing $0.05 \%$ Tween 20 and $3 \%$ BSA for $1 \mathrm{~h}$ at RT. After incubation, membranes were rinsed with PBS containing 0.05\% Tween 20 and Concanavalin A reactivity was revealed using streptavidin-HRP (Bio-Rad).

Immunoreactive bands were visualized by enhanced chemiluminescence detection (Advance, GE Healthcare Life Sciences) and acquired with LAS 1000 apparatus (Fujifilm). For semiquantitative analysis of each protein, band density in every sample was calculated using Total lab TL120 (Nonlinear Dynamics). Data were normalized for protein concentration using $\beta$-actin as loading control. Results are representative of three replicates on four animals per brain area examined.

Whole-cell patch-clamp recordings. The preparation of PFC slices was performed as previously described (Gonzalez-Islas and Hablitz, 2003). Briefly, male WT and MAO A KO mice were anesthetized with halothane and killed. A block of tissue containing PFC was rapidly dissected and sliced in the coronal plane $(300 \mu \mathrm{m})$ with a vibratome (Leica VT1000S) in ice-cold low- $\mathrm{Ca}^{2+}$ solution containing the following (in $\mathrm{mm}$ ): $126 \mathrm{NaCl}, 1.6 \mathrm{KCl}, 1.2 \mathrm{NaH}_{2} \mathrm{PO}_{4}, 1.2$ $\mathrm{MgCl}_{2}, 0.625 \mathrm{CaCl}_{2}, 18 \mathrm{NaHCO}_{3}$, and 11 glucose. Slices were transferred to a holding chamber with artificial CSF $\left(\mathrm{ACSF}, 37^{\circ} \mathrm{C}\right)$ saturated with $95 \% \mathrm{O}_{2}$ and $5 \% \mathrm{CO}_{2}$ containing the following (in $\mathrm{mm}$ ): $126 \mathrm{NaCl}, 1.6 \mathrm{KCl}, 1.2$ $\mathrm{NaH}_{2} \mathrm{PO}_{4}, 1.2 \mathrm{MgCl}_{2}, 2.4 \mathrm{CaCl}_{2}, 18 \mathrm{NaHCO}_{3}$, and 11 glucose. Slices (four per animal) were allowed to recover for at least $1 \mathrm{~h}$ before being placed in the recording chamber and superfused with the ACSF $\left(37^{\circ} \mathrm{C}\right)$ saturated with $95 \% \mathrm{O}_{2}$ and $5 \% \mathrm{CO}_{2}$. Cells were visualized using an upright microscope with infrared illumination (Axioskop FS 2 plus, Zeiss), and whole-cell voltage-clamp recordings (one per slice) were made by using an Axopatch 200B amplifier (Molecular Devices). Voltage-clamp experiments isolating NMDA-mediated EPSCs were performed with electrodes filled with a solution containing the following (in $\mathrm{mM}$ ): 20 $\left[{ }^{117} \mathrm{Cs}\right]$ methanesulfonic acid, HEPES, 0.4 EGTA, $2.8 \mathrm{NaCl}$, 5 TEA-Cl, $2.5 \mathrm{Mg}_{2} \mathrm{ATP}$, and $0.25 \mathrm{Mg}_{2} \mathrm{GTP}$, pH 7.2-7.4 (275-285 mOsm). Picrotoxin $(100 \mu \mathrm{M})$ and CNQX $(10 \mu \mathrm{M})$ were added to the ACSF to block GABA $_{\mathrm{A}}$ - and AMPA-mediated PSCs and to isolate NMDA-mediated EPSCs. Experiments began after series resistance reached stability (typically $15-40 \mathrm{M} \Omega$ ). Series and input resistance were monitored continuously on-line with a $5 \mathrm{mV}$ depolarizing step $(25 \mathrm{~ms})$. Data were filtered at $2 \mathrm{kHz}$, digitized at $10 \mathrm{kHz}$, and collected on-line with acquisition software (pClamp 8.2, Molecular Devices). Layer II/III py-
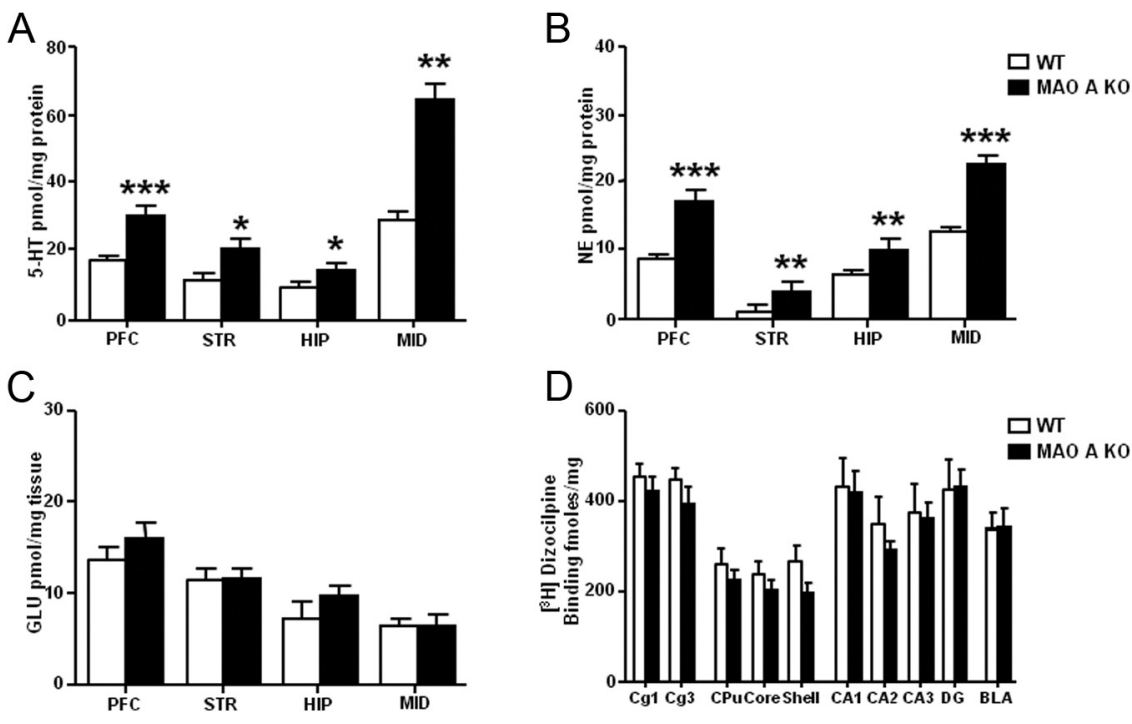

Figure 1. MAOA-deficient mice showed significantly higher $5-\mathrm{HT}$ and NE levels in all brain regions, but similar glutamate levels and NMDAR binding in comparison with WT mice. $A, H P L C$ analysis revealed higher 5 - HT concentrations in the PFC, striatum (STR), hippocampus (HIP), and midbrain (MID) of MAO A KO mice. $\boldsymbol{B}$, NE levels were also significantly greater than those in WT mice across all brain regions tested. $\boldsymbol{C}$, No alterations in glutamate levels were found in any brain region tested. $\boldsymbol{D}$, Autoradiography showed no differences in NMDAR binding in the cortical cingulate layers 1 and 3, striatal caudate-putamen, nucleus accumbens shell and core, hippocampal cornu ammonis areas 1, 2, and 3, dentate gyrus, and basal lateral amygdala. Values are represented as mean \pm SEM. ${ }^{*} p<0.05,{ }^{* *} p<0.01$, and ${ }^{* * *} p<0.001$ compared with WT mice. Cg1, Cingulate layer 1; Cg3, cingulate layer 3; CPu, caudateputamen; Core, nucleus accumbens core; Shell, nucleus accumbens shell; CA1, cornu ammonis area 1; CA2; CA3, cornu ammonis area 3; DG, dentate gyrus; BLA, basolateral amygdala.
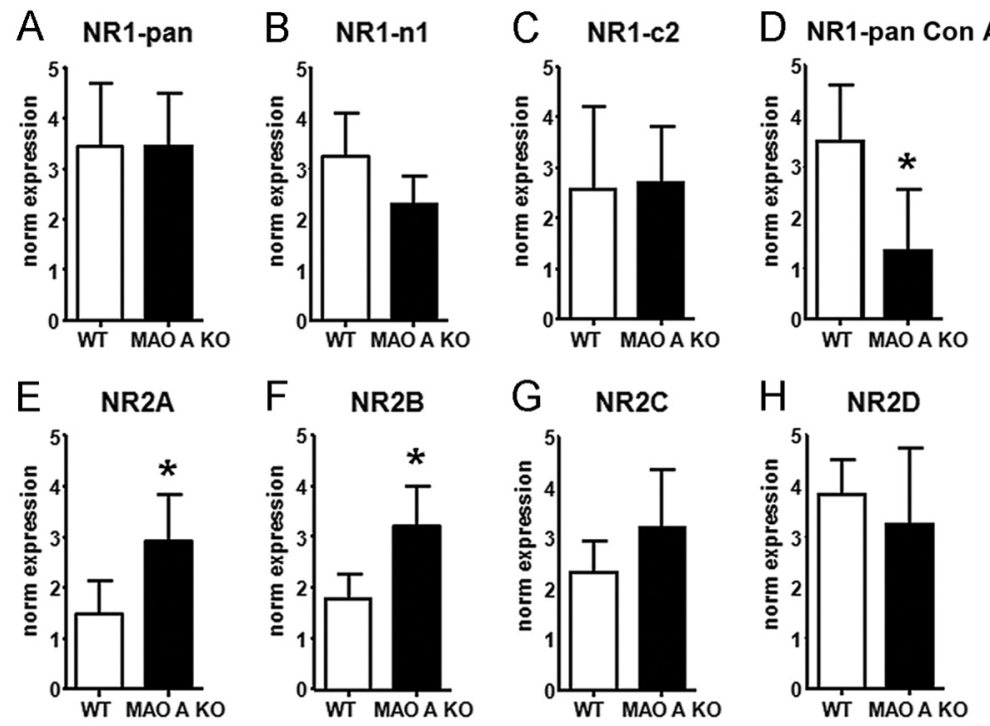

Figure 2. MAO A KO mice exhibited significant alterations in NMDA receptor subunit expression in the prefrontal cortex. $\boldsymbol{A}-\boldsymbol{D}$, Although no alterations in NR1 or its variants were detected, MAO A-deficient animals showed significantly lower levels of glycosylated NR1. $\boldsymbol{E}-\boldsymbol{H}$, Conversely, higher levels of NR2A and NR2B, but not NR2C or NR2D, subunit expression in the prefrontal cortex were found in MAO A mutants compared with their WT counterparts. Values are represented as mean \pm SEM. ${ }^{*} p<0.05$ compared with WT mice. Con A, concanavalin A. For further details, see text.

ramidal neurons were identified by their pyramidal shape, presence of a prominent apical dendrite, and the distance from the pial surface. A bipolar stainless steel stimulating electrode (FHC) was placed $100 \mu \mathrm{m}$ rostral to the recording electrode and was used to stimulate at a frequency of $0.1 \mathrm{~Hz}$ (pulse duration $50 \mu \mathrm{s}$ ). The amplitudes of NMDA-EPSCs were calculated by taking a $30 \mathrm{~ms}$ window after the peak of the EPSC and comparing this with the $5 \mathrm{~ms}$ window immediately before the stimulation artifact. 
Table 1. Normalized expression of NMDA subunits in striatum and hippocampus

\begin{tabular}{|c|c|c|c|c|c|c|}
\hline & NR1-pan & & NR2A & & NR2B & \\
\hline & WT & MAO A KO & WT & MAO A KO & WT & MAO A KO \\
\hline Striatum & $2.46 \pm 1.54$ & $2.86 \pm 1.56$ & $3.09 \pm 1.27$ & $2.27 \pm 0.86$ & $2.16 \pm 0.94$ & $3.61 \pm 0.79$ \\
\hline Hippocampus & $1.99 \pm 0.63$ & $2.89 \pm 0.78$ & $2.85 \pm 1.01$ & $3.02 \pm 1.26$ & $3.78 \pm 0.83$ & $3.52 \pm 0.62$ \\
\hline
\end{tabular}

A

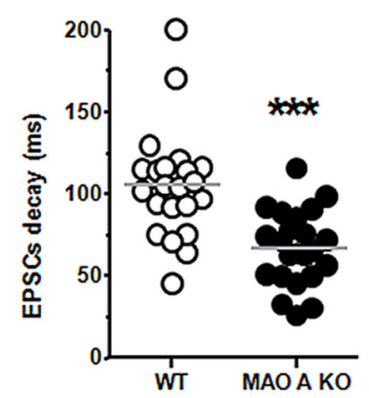

B
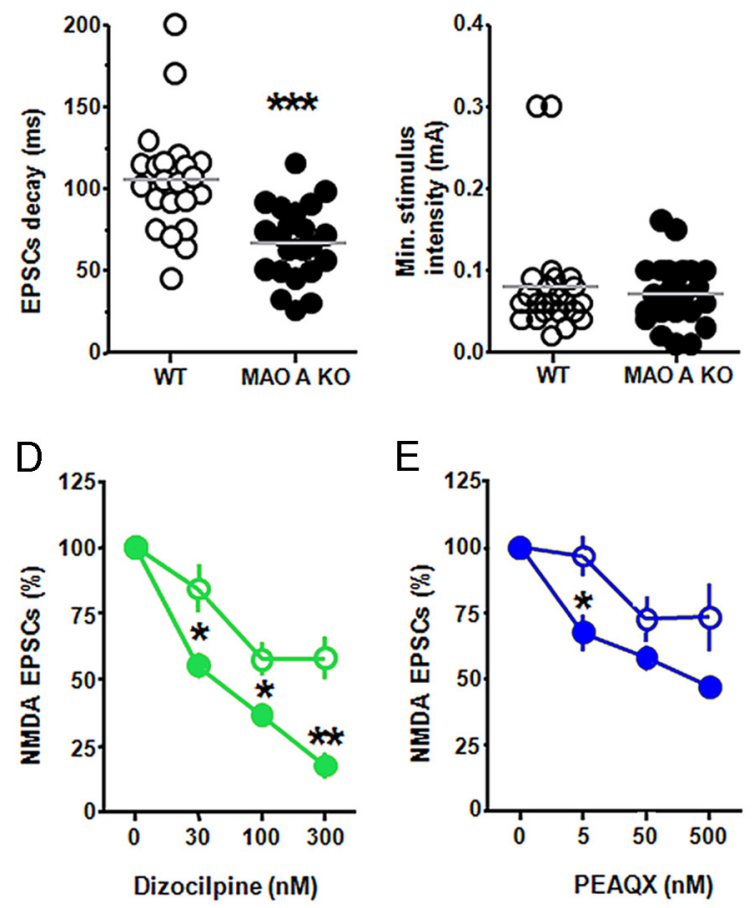

E

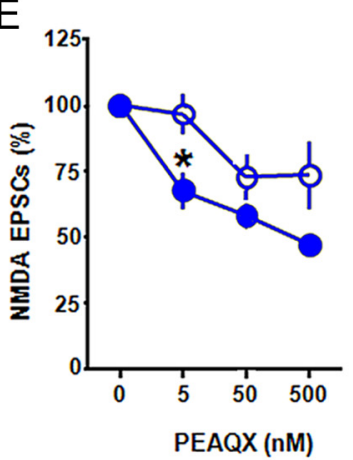

C

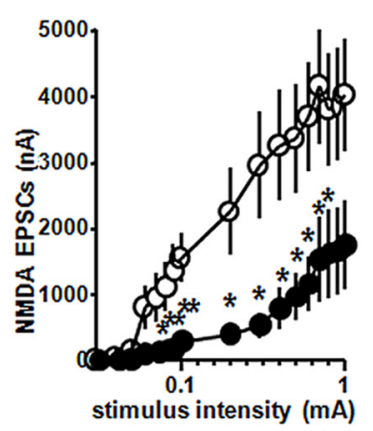

F

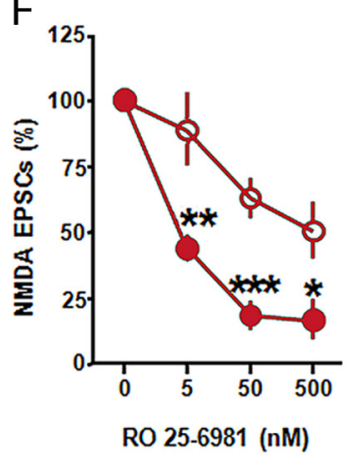

Figure 3. MAO A-deficient mice exhibited marked alterations in electrophysiological properties of NMDARs in the prefrontal cortex. $\boldsymbol{A}-\boldsymbol{C}$, In comparison to their WT counterparts, MAO A KO mice displayed a reduction in EPSC decay time and amplitude of NMDA EPSCs, but no changes in minimum stimulus intensity. $\boldsymbol{D}-\boldsymbol{F}, \mathrm{MAO}-\mathrm{A}$ KO mice showed a greater decrease in percent NMDA EPSCs than WT mice following treatment with the NMDA receptor antagonist dizocilpine, the NR2A subunit-specific inhibitor PEAQX, and the NR2B subunit blocker Ro 25-6981. Values are represented as mean \pm SEM. ${ }^{*} p<0.05,{ }^{* *} p<0.01$, and ${ }^{* * *} p<$ 0.001 compared to WT mice. Open/white circles, WT; closed/colored circles, MAO A KO.

Locomotor activity. Locomotor behavior was tested in a familiar arena, consisting of a Plexiglas square gray arena $(40 \times 40 \mathrm{~cm})$ surrounded by 4 black walls (40 cm high). On the floor, 2 zones of equivalent areas were defined: a central square quadrant of $28.28 \mathrm{~cm}$ per side, and a concentric peripheral frame including the area within $11.72 \mathrm{~cm}$ from the walls. Mice were first habituated to the apparatus for 3 consecutive days, in $5 \mathrm{~min}$ testing sessions. On the fourth day, mice were treated, and placed in the center of the arena after $30 \mathrm{~min}$. Locomotor behavior was monitored for $5 \mathrm{~min}$. Light and background noise in the room were kept at 10 lux and 70 $\mathrm{dB}$ respectively. Locomotor tracking was performed with Ethovision software (Noldus).

Resident-intruder test. Testing was performed as previously indicated (Bortolato et al., 2011). Male mice were isolated for $14 \mathrm{~d}$ in their home cages before testing. The choice of this duration was based on previous studies in our laboratory, which have assessed that this regimen is sufficient to evoke robust reactive aggressive responses in 129S6 MAO A KO mice, but not WT littermates (Bortolato et al., 2011). Following isolation, resident mice were habituated to the experimental room for $30 \mathrm{~min}$. Light and sound were maintained at $10 \mathrm{lux}$ and $70 \mathrm{~dB}$, respectively. Mice were exposed to age- and weight-matched WT males (previously acclimated to the same room) from different litters, for $5 \mathrm{~min}$. Behavior was videomonitored from an adjacent room, recorded and scored by trained observers unaware of the genotype. Measures included: (1) attack latency, (2) attack duration (total), (3) number of aggressive bouts, and (4) total locomotor activity, measured as number of crossings on a grid superimposed onto the image of each cage in the video monitor.
Statistical analyses. Normality and homoscedasticity of data distribution were verified using the Kolmogorov-Smirnov and Bartlett's test. Parametric analyses were performed with one-way or two-way ANOVA, as appropriate, followed by Tukey's test with Spjøtvoll-Stoline correction for post hoc comparisons. Nonparametric comparisons were performed by Kruskal-Wallis test, with Nemenyi's test for post hoc comparisons. Significance threshold was set at $p=0.05$.

\section{Results}

Brain-regional 5-HT, NE, and glutamate levels

As expected, 5-HT and NE content was increased throughout all brain regions of MAO A KO mice (Fig. $1 A, B$ ), including the PFC (5-HT: $F_{(1,9)}=25.91 ; p<0.001$; NE: $\left.F_{(1,9)}=23.19 ; p<0.001\right)$, striatum $\left(5-\mathrm{HT}: F_{(1,8)}=7.36 ; p<0.05 ; \mathrm{NE}: F_{(1,8)}=\right.$ 13.95; $p<0.01$ ), hippocampus (5-HT: $F_{(1,9)}=7.00 ; p<0.05 ; \mathrm{NE}: F_{(1,9)}=15.35$; $p<0.01)$ and midbrain (5-HT: $F_{(1,9)}=$ $12.32 ; p<0.01 ; \mathrm{NE}: F_{(1,8)}=63.57 ; p<$ 0.001 ). Conversely, the analysis of glutamate content across the same brain regions of WT and MAO A KO mice revealed no significant differences between genotypes (Fig. 1C).

\section{$\left[{ }^{3} \mathrm{H}\right]$ Dizocilpine binding sites}

Autoradiographic analyses revealed no differences in $\left[{ }^{3} \mathrm{H}\right]$ dizocilpine binding between WT and MAO A KO mice across any tested forebrain region, including $\mathrm{PFC}(\mathrm{Cg} 1$ and $\mathrm{Cg} 3)$, dorsal striatum $(\mathrm{CPu})$, nucleus accumbens (Shell and Core), hippocampus (CA1, CA2, CA3, DG) and basolateral amygdala (Fig. 1D).

\section{Immunoblotting of NMDA subunits}

We then examined the expression of NMDAR subunits NR1, NR2A, and NR2B in brain-regional synaptosomes of MAO A KO and WT mice. In the PFC (Fig. 2), no differences were found in NR1 total expression (NR1-Pan) (Fig. 2A) or in the levels of its splice variants n1 (Fig. $2 B$ ) and c2 (Fig. 2C). Nevertheless, immunoblotting with the mannose-associating lectin concanavalin A revealed a significantly lower glycosylation level in the NR1 subunits of MAO A mutants $\left(F_{(1,6)}=6.68 ; p<0.05\right)$ (Fig. $\left.2 D\right)$. In contrast, $\mathrm{MAO}$ A KO mice displayed significantly higher expressions of NR2A (Fig. $2 E)\left(F_{(1,6)}=6.56 ; p<0.05\right)$ and NR2B (Fig. $2 F)\left(F_{(1,6)}=9.50 ; p<0.05\right)$, but not NR2C (Fig. $\left.2 G\right)$ or NR2D (Fig. $2 \mathrm{H}$ ). No significant differences in either the glycosylation of NR2 subunits or NR2A:NR2B ratio (WT: $1.12 \pm 0.08$; MAO A KO: $1.50 \pm 0.13, p<0.10$ ) were found. The expression of NMDAR subunits in the striatum or hippocampus was comparable between the two genotypes (Table 1). 


\section{Ex vivo electrophysiology}

As the biophysical and pharmacological properties of NMDAR are known to reflect differences in its subunit composition (Monyer et al., 1994; Mori and Mishina, 1995; Cull-Candy et al., 2001), the finding of higher expression of NR2A and NR2B subunits in the PFC of MAO A KO mice prompted us to study the characteristics of NMDAR-mediated currents in this region. In comparison with their WT controls, MAO A KO mice showed a highly significant reduction in the decay time of EPSCs (Fig. $3 \mathrm{~A}$ ) $\left(F_{(1,33)}=15.39 ; p<0.001\right)$. While the minimum stimulus intensities were equivalent between the two genotypes (Fig. $3 B)\left(F_{(1,34)}=\right.$ 0.19 ; NS), EPSC amplitudes were significantly lower in MAO A $\mathrm{KO}$ mice (Fig. $3 C$ ) in correspondence of the range of stimulus intensities between $0.08 \mathrm{nA}$ and $0.8 \mathrm{nA}[p<0.05$ at $0.08 \mathrm{nA} ; p<$ 0.01 at 0.09 and $0.1 \mathrm{nA} ; p<0.05$ at $0.2-0.8 \mathrm{nA}]$. Following the measurement of the physiological differences of NMDARs between the two genotypes, we studied the responses of these targets to their antagonists. Administration of dizocilpine produced a significant reduction in the percentage of NMDA EPSCs in MAO A KO mice at all tested doses (Fig. 3D) $[p<0.05$ at 30 and $100 \mathrm{nM}$; $p<0.01$ at $300 \mathrm{~nm}$. The NR2A-specific antagonist PEAQX decreased NMDA EPSCs in MAO A KO mice; this effect was particularly evident at the lowest dose of PEAQX (Fig. $3 E$ ) $[p<0.05$ at $5 \mathrm{~nm} ; p<0.10$ at $500 \mathrm{~nm}$ ]. Finally, the NR2B subunit-specific antagonist Ro 25-6981 elicited a significant reduction in NMDA EPSCs at all doses tested (Fig. $3 F)(p<0.01$ at $5 \mathrm{~nm} ; p<0.001$ at $50 \mathrm{~nm} ; p<0.05$ at $500 \mathrm{~nm}$ ).

\section{Locomotor activity}

To explore the behavioral impact of altered NMDAR function, we evaluated the locomotor responses of selective antagonists on NMDARs containing NR2A and NR2B subunits in MAO A KO mice. We first examined the behavior of WT and MAO A KO mice to the NMDAR antagonist dizocilpine $(0.1 \mathrm{mg} / \mathrm{kg}$, i.p. $)$. As expected, saline-treated MAO A KO mice exhibited a reduction in locomotor activity, albeit not significant. Dizocilpine elicited a significant increment of locomotor activity in WT mice (Fig. $4 B$ ) (genotype $\times$ time: $F_{(1,36)}=6.49 ; p<0.05$; $p<0.05$ for WT-DIZ vs WT-SAL), but not in MAO A KO mutants. The higher dose of dizocilpine $(0.3 \mathrm{mg} / \mathrm{kg}$, i.p. $)$ induced severe ataxia and stereotyped behavior in MAO A KO mice, but not in WT littermates (data not shown). Administration of the NR2A antagonist PEAQX (2 mg/kg, i.p.) or the NR2B subunit antagonist Ro 25-6981 (5 mg/kg, i.p.) failed to significantly alter locomotor activity (Fig. 4B,C) (NR2A: $F_{(1,29)}=0.52$; NS and NR2B: $F_{(1,31)}=0.08$; NS).

\section{Resident-intruder aggression assay}

After the assessment of the locomotor responses of WT and MAO A KO mice to NMDAR antagonists, we proceeded to measure the impact of these drugs on the resident-intruder aggression paradigm.

Dizocilpine $(0.1 \mathrm{mg} / \mathrm{kg}$, i.p.) elicited marked anti-aggressive effects on MAO A KO mice, as revealed by the significant increases in their latency to fight, which was normalized to the levels observed in WT animals (Fig. $5 A)\left(H_{(3,40)}=19.69 ; p<\right.$ $0.001 ; p<0.001$ for KO-SAL vs WT-SAL and KO-DIZ vs KO$\mathrm{SAL}$ ); this agent also reduced the number of fighting episodes in MAO A KO mice (Fig. $5 B$ ) (genotype $\times$ treatment: $F_{(1,37)}=$ $14.44 ; p<0.001 ; p<0.001$ for KO-SAL vs WT-SAL and KO-DIZ vs KO-SAL) and overall fighting duration (Fig. $5 C$ ) (genotype $X$ treatment: $F_{(1,37)}=16.88 ; p<0.001 ; p<0.001$ for KO-SAL vs WT-SAL and KO-DIZ vs KO-SAL). In partial agreement with our previous results in the open field, the drug did not induce any
A

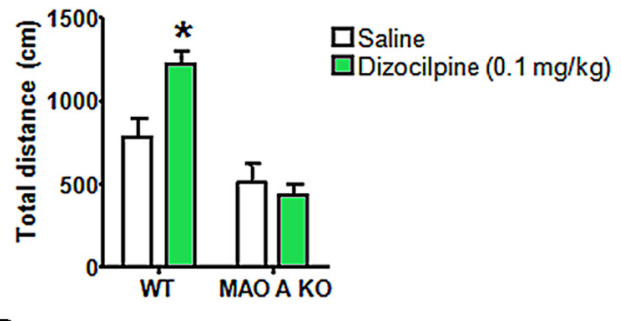

B

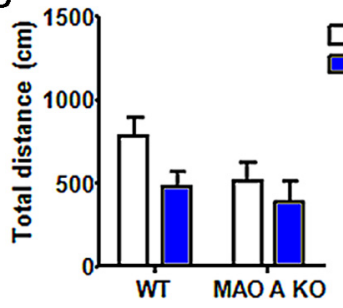

C

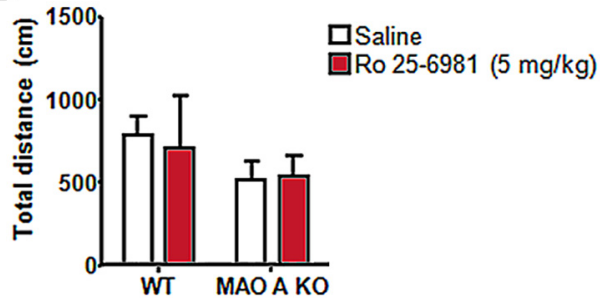

Figure 4. Dizocilpine altered locomotor activity in WT, but not in MAO A mutant mice. $\boldsymbol{A}$, Dizocilpine elicited a significant increase in total distance traveled by WT mice. $B, C$, Both NR2A and NR2B subunit antagonism showed comparable effects in both genotypes in all parameters tested. Values are represented as mean \pm SEM. ${ }^{*} p<0.05$ compared with WT mice treated with saline.

significant change in locomotor activity in either genotype (data not shown).

Both PEAQX (2 mg/kg, i.p.) and Ro 25-6981 (5 mg/kg, i.p.) also elicited a profound reduction of aggressive behaviors, with significant increases in the latencies to the first fighting approach (Fig. $5 D, G)\left(\mathrm{NR} 2 \mathrm{~A}: H_{(3,38)}=18.46 ; p<0.001\right.$ and NR2B: $H_{(3,40)}=21.54 ; p<0.001$ ), number of fighting episodes (Fig. $5 E, H)\left(\mathrm{NR} 2 \mathrm{~A}: F_{(1,35)}=6.08 ; p<0.05\right.$ and NR2B: $F_{(1,37)}=11.65$; $p<0.01$ ), and overall duration of fighting (Fig. $5 F, I)$ (NR2A: $F_{(1,35)}=9.56 ; p<0.01$ and NR2B: $\left.F_{(1,37)}=10.57 ; p<0.01\right)$. Post hoc analyses confirmed that saline-treated MAO A KO mice displayed a significantly shorter latency to fight (NR2A: $p<0.001$ and NR2B: $p<0.001$ ), higher number of fighting bouts (NR2A: $p<0.001$ and NR2B: $p<0.001)$ and longer fighting duration (NR2A: $p<0.001$ and NR2B: $p<0.001$ ) than their WT counterparts. Moreover, PEAQX and Ro 25-6981 administration significantly increased the latency to fight (NR2A: $p<0.01$ and NR2B: $p<0.001$ ) and decreased fighting frequency (NR2A: $p<0.001$ and NR2B: $p<0.001$ ) and duration (NR2A: $p<0.001$ and NR2B: $p<0.001)$ in MAO A KO mice.

\section{Discussion}

We showed that the PFC of MAO A-deficient mice exhibited significant variations of synaptic expression of NMDAR subunits, including increases in NR2A and NR2B and marked deficits in $N$-glycosylated NR1. These imbalances led to overt abnormalities of NMDAR properties, including marked reductions of decay time and excitability, as well as hypersensitivity to dizocilpine and selective NR2A and NR2B blockers. Notably, sys- 
A

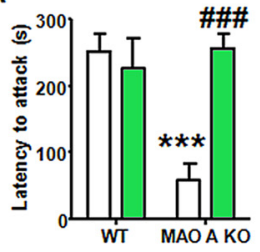

D

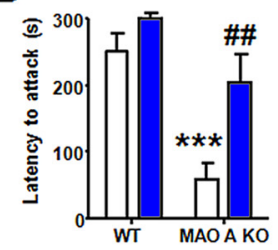

$\mathrm{G}$

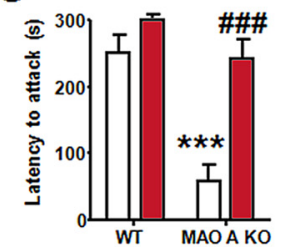

B

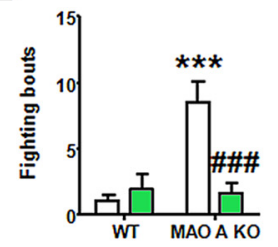

E

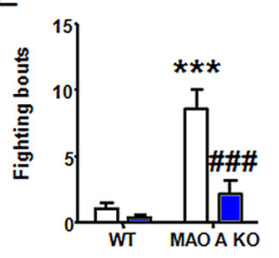

$\mathrm{H}$

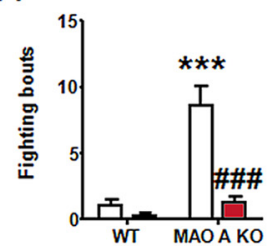

C

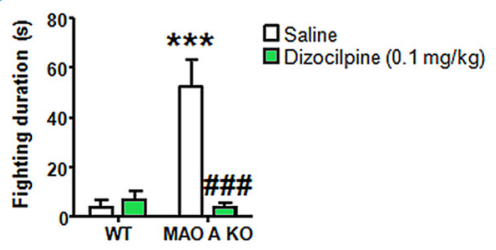

F
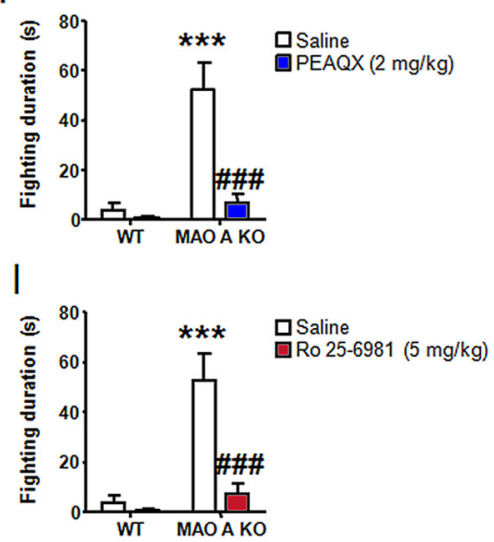

Figure 5. Dizocilpine, PEAQX, and Ro 25-6981 significantly decreased aggression in MAO A-deficient mice. A-C, NMDAR antagonism elicited a significant increase in latency to fight, as well as reduced the fighting frequency and duration in MAO A KO mice. $\boldsymbol{D}-\boldsymbol{F}$, Similarly, MAO A mutants displayed an increase in latency to fight and engaged in lower fighting bouts and duration following NR2A subunit antagonism. G-I, NR2B inhibition significantly elevated the latency, and decreased the bouts and overall duration of fighting behavior in MAO A KO mice. Values represented as mean \pm SEM. ${ }^{* * *} p<0.001$ compared with saline-treated WT mice; ${ }^{\# \#} p<0.01$ and ${ }^{\# \# \#} p<0.001$ compared with MAO A KO mice treated with saline.

temic administration of these agents to $\mathrm{MAO} \mathrm{A} \mathrm{KO}$ mice reduced aggression to a degree comparable to those observed in WT littermates, without affecting locomotor activity.

These findings collectively suggest that MAO A modulates aggressive behaviors by controlling the structure and function of synaptic NMDARs in the PFC. Cogent evidence documents that $\mathrm{PFC}$ is a key player in the modulation of aggression and allows for the emotional appraisal of socio-affective and environmental stimuli and the initiation of appropriate behavioral responses (Davidson, 2002; Phillips et al., 2003; Ochsner and Gross, 2005). Pyramidal neurons in the PFC integrate multiple synaptic signals from different brain areas, and project to main components of the limbic-subcortical circuit that regulate negative affect and reactive aggression, such as the amygdaloid nuclei, medial hypothalamus and dorsal periaqueductal gray (Panksepp, 1998; Gregg and Siegel, 2001). The NMDAR works as a "coincidence detector" that enables the spatial and temporal summation of converging inputs (Seeburg et al., 1995). This mechanism plays a pivotal role in the dynamic coordination of information processing, insofar as it allows for the amplification of contextually pertinent signals and the suppression of irrelevant stimuli (Phillips et al., 2010). Furthermore, NMDARs are instrumental for the activation of PFC pyramidal neurons (Shi and Zhang, 2003; Jackson et al., 2004), as well as their interactions with interneurons (Homayoun and Moghaddam, 2007). Thus, the observed reductions in decay time and excitability in prefrontal NMDARs are likely to decrease the temporal integration of nonsynchronous synaptic inputs, and impair the ability of pyramidal neurons to regulate emotional processing of social and environmental stimuli (Rolls et al., 2008). The involvement of prefrontal NMDARs in the link between MAO A and the vulnerability to reactive aggression complements previous reports documenting PFC alterations in male carriers of low-activity MAOA allelic variants (Meyer-Lindenberg et al., 2006; Lee and Ham, 2008). These perturbations are conducive to a negative bias in the emotional appraisal of ambiguous socio-affective and contextual cues (Passamonti et al., 2006; Eisenberger et al., 2007; Brummett et al., 2008; Lee and Ham, 2008; McDermott et al., 2009), thereby enhancing the predisposition to reactive aggression in response to adverse experiences, particularly during early developmental stages (Buckholtz and MeyerLindenberg, 2008). Notably, MAO A KO mice exhibit alterations in risk assessment and paradoxical defensive reactivity to neutral and predator cues (Bortolato and Shih, 2011; Godar et al., 2011).

The increments in synaptic NR2A and NR2B in the PFC of MAO A-deficient mice were not paralleled by changes in the total levels of NR1 (or its splice cassettes), NR2C or NR2D, but rather by a marked reduction of NR1 N-glycosylation, as revealed by immunoblotting with the mannose-associating lectin concanavalin A. N-Glycosylation processes occur at the membrane of the endoplasmic reticulum and require the activation of a poorly defined set of glycosyltransferase complexes (Ivatt, 1981; Kornfeld and Kornfeld, 1985; Burda and Aebi, 1999). The observed alterations may result from functional impairments of this enzymatic machinery; accordingly, previous studies showed that, in cortical neurons, the inhibition of the first enzymatic step of $N$-glycosylation enhances the degradation of nonglycosylated NR1, but not NR2A subunits (Gascón et al., 2007). The extensive $N$-glycosylation of NR1 (based on the attachment of highmannose oligosaccharide side-chains onto 12 Asparagine sites) is essential for its oligomerization with NR2 subunits (Chazot et al., 1995; Standley and Baudry, 2000); thus, the increased expression in NR2A and NR2B may be paralleled by a reduced number of functional NR1 subunits. These variations leave the total NMDAR number unaffected (as confirmed by our dizocilpine binding analyses), but lead to pronounced alterations of the stoichiometric relations among subunits within each channel.

Changes in NR2A and NR2B subunit composition provide differential contributions to the temporal dynamics and conductance of the NMDA channel, as well as its modulatory role on synaptic plasticity mechanisms (Liu et al., 2004; Massey et al., 2004; Foster et al., 2010). Therefore, our observations may reflect the combined increments of both NR2A and NR2B subunits. Indeed, increases in NR2A subunits are linked to accelerated NMDA current kinetics (Carmignoto and Vicini, 1992; Flint et al., 1997; Vicini et al., 1998), whereas increments in NR2B subunits may affect the amplitude of NMDAR currents (Vicini et al., 1998). Since NR2A and NR2B regulate dendritic length and size (Ewald et al., 2008; Sepulveda et al., 2010), their increased expression may also partially account for the changes in dendritic arborization in PFC pyramidal neurons of MAO A-deficient mice (Bortolato et al., 2011).

The neurochemical underpinnings of the reduction in $N$-glycosylated NR1 and increase in NR2A and NR2B subunits in the $\mathrm{PFC}$ remain unknown. MAO A is a critical regulator of the homeostatic balance of 5-HT and NE in the brain, and its defi- 
ciency results in marked perturbations in the signaling of these monoamines (Shih et al., 1999; Bortolato and Shih, 2011). Although the observed changes in NR1 glycosylation and NMDAR subunit expression may be underpinned by increases in 5-HT and/or NE levels, this possibility is tempered by the observation that the changes in NMDARs were only found in the PFC, in contrast with the ubiquitous enhancements in monoamine concentrations across all brain areas. The regional selectivity of the structural variations of NMDARs may instead reflect the activation of 5-HT or NE receptors which are particularly abundant in prefrontal pyramidal neurons, such as $5-\mathrm{HT}_{1 \mathrm{~A}}$ or $5-\mathrm{HT}_{2 \mathrm{~A}}$. Accordingly, activation of $5-\mathrm{HT}_{1 \mathrm{~A}}$ receptors has been found to modulate the expression of NMDAR subunits in these cells (Yuen et al., 2005). Further studies will be needed to evaluate the neurodevelopmental role of $\mathrm{NE}$ and other neurochemical targets in the structural, biophysical and pharmacological properties of NMDARs in MAO A KO mice.

Alterations in NR2A and NR2B subunit expression patterns have been linked to neurodevelopmental changes (Monyer et al., 1994; Sheng et al., 1994; Zhong et al., 1995; Portera-Cailliau et al., 1996; van Zundert et al., 2004), which may play relevant roles in the modulation of corticogenesis (Barth and Malenka, 2001; Philpot et al., 2001; Fagiolini et al., 2003; Yoshimura et al., 2003). In rodents, the cortical distribution of NR2B is very abundant throughout prenatal and early postnatal stages, but tends to decrease after the first postnatal week; conversely, NR2A expression is barely detectable at birth, but increases with age (Monyer et al., 1994; Mori and Mishina, 1995). The behavioral deficits of MAO A KO mice are likely supported by early neurodevelopmental processes; for example, normalization of 5-HT brain levels during the first weeks of postnatal life rescues several phenotypic alterations in MAO A KO mice (Cases et al., 1995). Building on these premises, it may be hypothesized that early alterations in monoaminergic neurotransmission in male MAO A-deficient subjects may be conducive to persistent alterations in NMDA subunit expression, which may in turn disrupt PFC connectivity and increase aggression vulnerability.

The alterations in NR2A and NR2B expression also affected the pharmacological responses of prefrontal NMDARs. In line with previous evidence (Mori and Mishina, 1995), the increased NR2A and NR2B distribution induced hypersensitivity to NMDAR antagonists. Administration of these agents significantly reduced resident-intruder aggression in MAO A KO mice, as signified by the marked decrease in overall duration and number of fighting episodes, as well as by the significant increase in latency to the first attack. These changes were not accompanied by variations in locomotor activity in MAO A KO mice, suggesting a specific anti-aggressive effect of NMDAR antagonists. Nevertheless, given that our behavioral analyses were only limited to the measurement of impulsive aggressive responses in MAO A KO mice, we cannot exclude that the observed actions of NMDAR antagonists may reflect other underlying emotional alterations.

The available preclinical evidence indicates that NMDAR antagonists yield highly variable effects in experimental models of aggression; in fact, whereas these agents increase fighting responses in rodents with low proclivity to aggression, they yield the opposite effects in aggressive counterparts (Miczek and Fish, 2006). These apparent discrepancies may reflect the inability of most rodent paradigms to distinguish between reactive and instrumental aggression (Nelson and Trainor, 2007); in this perspective, it is worth noting that the striking isomorphism of the endophenotypes of MAO A-deficient mice with the behavioral repertoire of impulsive antisocial manifestations in humans suggest a high predictive validity of these models for the development of anti-aggressive agents. The high translational relevance of our results points to low-dose NMDAR antagonists (or selective NR2A and NR2B blockers) as valuable therapeutic options for reactive aggression. Accordingly, recent studies have highlighted the potential of low-dose or low-potency NMDA antagonists as efficacious antiaggressive treatments in several neuropsychiatric disorders (Bachenberg, 1998; Wilcock et al., 2008; Ballard et al., 2009).

In summary, the present findings highlight NMDARs as promising targets in the treatment of antisocial aggressive traits in individuals with low MAO A activity. Future clinical studies are warranted to validate this intriguing possibility and fully establish the anti-aggressive properties of NMDAR blockers.

\section{References}

Alia-Klein N, Goldstein RZ, Kriplani A, Logan J, Tomasi D, Williams B, Telang F, Shumay E, Biegon A, Craig IW, Henn F, Wang GJ, Volkow ND, Fowler JS (2008) Brain monoamine oxidase A activity predicts trait aggression. J Neurosci 28:5099-5104.

Bachenberg KL (1998) Oral ketamine for the management of combative autistic adult. Anesthesiology 89:549-550.

Ballard CG, Gauthier S, Cummings JL, Brodaty H, Grossberg GT, Robert P, Lyketsos CG (2009) Management of agitation and aggression associated with Alzheimer disease. Nat Rev Neurol 5:245-255.

Barth AL, Malenka RC (2001) NMDAR EPSC kinetics do not regulate the critical period for LTP at thalamocortical synapses. Nat Neurosci 4:235-236.

Blair RJR (2004) The neurobiology of aggression. In: Neurobiology of mental illness, Ed 2 (Charney DS, Nestler EJ, eds), pp 1076-1085. New York: Oxford UP.

Bortolato M, Shih JC (2011) Behavioral outcomes of monoamine oxidase deficiency: preclinical and clinical evidence. Int Rev Neurobiol 100:13-42.

Bortolato M, Chen K, Shih JC (2008) Monoamine oxidase inactivation: from pathophysiology to therapeutics. Adv Drug Deliv Rev 60:1527-1533.

Bortolato M, Chen K, Godar SC, Chen G, Wu W, Rebrin I, Farrell MR, Scott AL, Wellman CL, Shih JC (2011) Social deficits and perseverative behaviors, but not overt aggression, in MAO-A hypomorphic mice. Neuropsychopharmacology 36:2674-2688.

Boyer PA, Skolnick P, Fossom LH (1998) Chronic administration of imipramine and citalopram alters the expression of NMDAR subunit mRNAs in mouse brain. A quantitative in situ hybridization study. J Mol Neurosci 10:219-233.

Brummett BH, Boyle SH, Siegler IC, Kuhn CM, Surwit RS, Garrett ME, Collins A, Ashley-Koch A, Williams RB (2008) HPA axis function in male caregivers: effect of the monoamine oxidase-A gene promoter (MAOA-uVNTR). Biol Psychol 79:250-255.

Brunner HG, Nelen M, Breakefield XO, Ropers HH, van Oost BA (1993) Abnormal behavior associated with a point mutation in the structural gene for monoamine oxidase A. Science 262:578-580.

Buckholtz JW, Meyer-Lindenberg A (2008) MAOA and the neurogenetic architecture of human aggression. Trends Neurosci 31:120-129.

Burda P, Aebi M (1999) The dolichol pathway of $N$-linked glycosylation. Biochim Biophys Acta 1426:239-257.

Carmignoto G, Vicini S (1992) Activity-dependent decrease in NMDAR responses during development of the visual cortex. Science 258:1007-1011.

Carobrez AP, Teixeira KV, Graeff FG (2001) Modulation of defensive behavior by periaqueductal gray NMDA/glycine-B receptor. Neurosci Biobehav Rev 25:697-709.

Cases O, Seif I, Grimsby J, Gaspar P, Chen K, Pournin S, Müller U, Aguet M, Babinet C, Shih JC, et al. (1995) Aggressive behavior and altered amounts of brain serotonin and norepinephrine in mice lacking MAOA. Science 268:1763-1766.

Caspi A, McClay J, Moffitt TE, Mill J, Martin J, Craig IW, Taylor A, Poulton R (2002) Role of genotype in the cycle of violence in maltreated children. Science 297:851-854.

Chazot PL, Cik M, Stephenson FA (1995) An investigation into the role of 
$\mathrm{N}$-glycosylation in the functional expression of a recombinant heteromeric NMDAR. Mol Membr Biol 12:331-337.

Cherek DR, Tcheremissine OV, Lane SD (2006) Psychopharmacology of human aggression: laboratory and clinical studies. In: Biology of aggression (Nelson RJ, ed), pp 424-446. New York: Oxford UP.

Clarke G, O’Mahony S, Malone G, Dinan TG (2007) An isocratic high performance liquid chromatography method for the determination of GABA and glutamate in discrete regions of the rodent brain. J Neurosci Methods 160:223-230.

Cull-Candy S, Brickley S, Farrant M (2001) NMDAR subunits: diversity, development and disease. Curr Opin Neurobiol 11:327-335.

Davidson RJ (2002) Anxiety and affective style: role of prefrontal cortex and amygdala. Biol Psychiatry 51:68-80.

Daw NW, Stein PS, Fox K (1993) The role of NMDARs in information processing. Annu Rev Neurosci 16:207-222.

Durand GM, Bennett MV, Zukin RS (1993) Splice variants of the $N$-methyl-Daspartate receptor NR1 identify domains involved in regulation by polyamines and protein kinase C. Proc Natl Acad Sci U S A 90:6731-6735.

Eisenberger NI, Way BM, Taylor SE, Welch WT, Lieberman MD (2007) Understanding genetic risk for aggression: clues from the brain's response to social exclusion. Biol Psychiatry 61:1100-1108.

Ewald RC, Van Keuren-Jensen KR, Aizenman CD, Cline HT (2008) Roles of NR2A and NR2B in the development of dendritic arbor morphology in vivo. J Neurosci 28:850-861.

Fagiolini M, Katagiri H, Miyamoto H, Mori H, Grant SG, Mishina M, Hensch TK (2003) Separable features of visual cortical plasticity revealed by $\mathrm{N}$-methyl-D-aspartate receptor 2A signaling. Proc Natl Acad Sci U S A 100:2854-2859.

Flint AC, Maisch US, Weishaupt JH, Kriegstein AR, Monyer H (1997) NR2A subunit expression shortens NMDAR synaptic currents in developing neocortex. J Neurosci 17:2469-2476.

Foster KA, McLaughlin N, Edbauer D, Phillips M, Bolton A, ConstantinePaton M, Sheng M (2010) Distinct roles of NR2A and NR2B cytoplasmic tails in long-term potentiation. J Neurosci 30:2676-2685.

Gascón S, García-Gallo M, Renart J, Díaz-Guerra M (2007) Endoplasmic reticulum-associated degradation of the NR1 but not the NR2 subunits of the $N$-methyl-D-aspartate receptor induced by inhibition of the $\mathrm{N}$-glycosylation in cortical neurons. J Neurosci Res 85:1713-1723.

Godar SC, Bortolato M, Frau R, Dousti M, Chen K, Shih JC (2011) Maladaptive defensive behaviours in monoamine oxidase A-deficient mice. Int J Neuropsychopharmacol 14:1195-1207.

Gonzalez-Islas C, Hablitz JJ (2003) Dopamine enhances EPSCs in layer IIIII pyramidal neurons in rat prefrontal cortex. J Neurosci 23:867-875.

Gould E, Cameron HA (1997) Early NMDAR blockade impairs defensive behavior and increases cell proliferation in the dentate gyrus of developing rats. Behav Neurosci 111:49-56.

Gregg TR, Siegel A (2001) Brain structures and neurotransmitters regulating aggression in cats: implications for human aggression. Prog Neuropsychopharmacol Biol Psychiatry 25:91-140.

Harris A, Lurigio AJ (2007) Mental illness and violence: a brief review of research and assessment strategies. Aggr Viol Behav 12:542-551.

Homayoun H, Moghaddam B (2007) NMDAR hypofunction produces opposite effects on prefrontal cortex interneurons and pyramidal neurons. J Neurosci 27:11496-11500.

Ivatt RJ (1981) Regulation of glycoprotein biosynthesis by formation of specific glycosyltransferase complexes. Proc Natl Acad Sci U S A 78:4021-4025.

Jackson ME, Homayoun H, Moghaddam B (2004) NMDAR hypofunction produces concomitant firing rate potentiation and burst activity reduction in the prefrontal cortex. Proc Natl Acad Sci U S A 101:8467-8472.

Kim JJ, Shih JC, Chen K, Chen L, Bao S, Maren S, Anagnostaras SG, Fanselow MS, De Maeyer E, Seif I, Thompson RF (1997) Selective enhancement of emotional, but not motor, learning in monoamine oxidase A-deficient mice. Proc Natl Acad Sci U S A 94:5929-5933.

Kim-Cohen J, Caspi A, Taylor A, Williams B, Newcombe R, Craig IW, Moffitt TE (2006) MAOA, maltreatment, and gene-environment interaction predicting children's mental health: new evidence and a meta-analysis. Mol Psychiatry 11:903-913.

Kornfeld R, Kornfeld S (1985) Assembly of asparagine-linked oligosaccharides. Annu Rev Biochem 54:631-664.

Lan NC, Chen CH, Shih JC (1989) Expression of functional human mono- amine oxidase A and B cDNAs in mammalian cells. J Neurochem $52: 1652-1654$.

Lee BT, Ham BJ (2008) Monoamine oxidase A-uVNTR genotype affects limbic brain activity in response to affective facial stimuli. Neuroreport 19:515-519.

Liu XB, Murray KD, Jones EG (2004) Switching of NMDAR 2A and 2B subunits at thalamic and cortical synapses during early postnatal development. J Neurosci 24:8885-8895.

Massey PV, Johnson BE, Moult PR, Auberson YP, Brown MW, Molnar E, Collingridge GL, Bashir ZI (2004) Differential roles of NR2A and NR2B-containing NMDARs in cortical long-term potentiation and longterm depression. J Neurosci 24:7821-7828.

Masuko T, Suzuki I, Kizawa Y, Kusama-Eguchi K, Watanabe K, Kashiwagi K, Igarashi K, Kusama T (2004) Monoamines directly inhibit $N$-methyl-Daspartate receptors expressed in Xenopus oocytes in a voltage-dependent manner. Neurosci Lett 371:30-33.

McDermott R, Tingley D, Cowden J, Frazzetto G, Johnson DD (2009) Monoamine oxidase A gene (MAOA) predicts behavioral aggression following provocation. Proc Natl Acad Sci U S A 106:2118-2123.

Meyer-Lindenberg A, Buckholtz JW, Kolachana B, R Hariri A, Pezawas L, Blasi G, Wabnitz A, Honea R, Verchinski B, Callicott JH, Egan M, Mattay V, Weinberger DR (2006) Neural mechanisms of genetic risk for impulsivity and violence in humans. Proc Natl Acad Sci U S A 103:6269-6274.

Miczek KA, Fish EW (2006) Monoamines, GABA, Glutamate, and Aggression. In: Biology of aggression (Nelson RJ, ed), pp 114-149. New York: Oxford UP.

Monyer H, Burnashev N, Laurie DJ, Sakmann B, Seeburg PH (1994) Developmental and regional expression in the rat brain and functional properties of four NMDARs. Neuron 12:529-540.

Mori H, Mishina M (1995) Structure and function of the NMDAR channel. Neuropharmacology 34:1219-1237.

Nelson RJ, Trainor BC (2007) Neural mechanisms of aggression. Nat Rev Neurosci 8:536-546.

Newell KA, Zavitsanou K, Huang XF (2007) Short and long term changes in NMDAR binding in mouse brain following chronic phencyclidine treatment. J Neural Transm 114:995-1001.

Ochsner KN, Gross JJ (2005) The cognitive control of emotion. Trends Cogn Sci 9:242-249.

Panksepp J (1998) Affective neuroscience-the foundations of human and animal emotions. New York: Oxford UP.

Passamonti L, Fera F, Magariello A, Cerasa A, Gioia MC, Muglia M, Nicoletti G, Gallo O, Provinciali L, Quattrone A (2006) Monoamine oxidase-a genetic variations influence brain activity associated with inhibitory control: new insight into the neural correlates of impulsivity. Biol Psychiatry 59:334-340.

Paxinos G, Fanklin KBJ (2001) The mouse brain in stereotaxic coordinates, Ed 2. San Diego: Academic.

Phillips ML, Drevets WC, Rauch SL, Lane R (2003) Neurobiology of emotion perception I: the neural basis of normal emotion perception. Biol Psychiatry 54:504-514.

Phillips WA, von der Malsburg C, Singer W (2010) Dynamic coordination in brain and mind. In: Dynamic coordination in the brain: from neurons to mind (von der Malsburg C, Phillips WA, Singer W, eds), pp 1-25. Cambridge, MA: MIT.

Philpot BD, Sekhar AK, Shouval HZ, Bear MF (2001) Visual experience and deprivation bidirectionally modify the composition and function of NMDARs in visual cortex. Neuron 29:157-169.

Portera-Cailliau C, Price DL, Martin LJ (1996) N-methyl-D-aspartate receptor proteins NR2A and NR2B are differentially distributed in the developing rat central nervous system as revealed by subunit-specific antibodies. J Neurochem 66:692-700.

Reiss D (1993) The long reach of violence and aggression. Psychiatry 56:163-165.

Rolls ET, Loh M, Deco G, Winterer G (2008) Computational models of schizophrenia and dopamine modulation in the prefrontal cortex. Nat Rev Neurosci 9:696-709.

Scott AL, Bortolato M, Chen K, Shih JC (2008) Novel monoamine oxidase A knock out mice with human-like spontaneous mutation. Neuroreport 19:739-743.

Seeburg PH, Burnashev N, Köhr G, Kuner T, Sprengel R, Monyer H (1995) The NMDAR channel: molecular design of a coincidence detector. Recent Prog Horm Res 50:19-34.

Sepulveda FJ, Bustos FJ, Inostroza E, Zúñiga FA, Neve RL, Montecino M, van 
Zundert B (2010) Differential roles of NMDAR Subtypes NR2A and NR2B in dendritic branch development and requirement of RasGRF1. J Neurophysiol 103:1758-1770.

Sheng M, Cummings J, Roldan LA, Jan YN, Jan LY (1994) Changing subunit composition of heteromeric NMDARs during development of rat cortex. Nature 368:144-147.

Shi WX, Zhang XX (2003) Dendritic glutamate-induced bursting in the prefrontal cortex: further characterization and effects of phencyclidine. J Pharmacol Exp Ther 305:680-687.

Shih JC, Chen K, Ridd MJ (1999) Monoamine oxidase: from genes to behavior. Annu Rev Neurosci 22:197-217.

Standley S, Baudry M (2000) The role of glycosylation in ionotropic glutamate receptor ligand binding, function, and trafficking. Cell Mol Life Sci 57:1508-1516.

van Zundert B, Yoshii A, Constantine-Paton M (2004) Receptor compartmentalization and trafficking at glutamate synapses: a developmental proposal. Trends Neurosci 27:428-437.

Vicini S, Wang JF, Li JH, Zhu WJ, Wang YH, Luo JH, Wolfe BB, Grayson DR (1998) Functional and pharmacological differences between recombinant $N$-methyl-D-aspartate receptors. J Neurophysiol 79:555-566.
Weder N, Yang BZ, Douglas-Palumberi H, Massey J, Krystal JH, Gelernter J, Kaufman J (2009) MAOA genotype, maltreatment, and aggressive behavior: the changing impact of genotype at varying levels of trauma. Biol Psychiatry 65:417-424.

Widom CS, Brzustowicz LM (2006) MAOA and the "cycle of violence:" childhood abuse and neglect, MAOA genotype, and risk for violent and antisocial behavior. Biol Psychiatry 60:684-689.

Wilcock GK, Ballard CG, Cooper JA, Loft H (2008) Memantine for agitation/aggression and psychosis in moderately severe to severe Alzheimer's disease: a pooled analysis of 3 studies. J Clin Psychiatry 69:341-348.

Yoshimura Y, Ohmura T, Komatsu Y (2003) Two forms of synaptic plasticity with distinct dependence on age, experience, and NMDAR subtype in rat visual cortex. J Neurosci 23:6557-6566.

Yuen EY, Jiang Q, Chen P, Gu Z, Feng J, Yan Z (2005) Serotonin 5-HT1A receptors regulate NMDAR channels through a microtubule-dependent mechanism. J Neurosci 25:5488-5501.

Zhong J, Carrozza DP, Williams K, Pritchett DB, Molinoff PB (1995) Expression of mRNAs encoding subunits of the NMDAR in developing rat brain. J Neurochem 64:531-539. 